\section{Anaesthesia for balloon dilatation for congenital tracheal stenosis in an infant}

To the Editor:

Long-segment congenital tracheal stenosis is difficult to treat surgically or conservatively. We experienced the perioperative management of such an infant treated with several sessions of balloon tracheal dilatation for a year until he finally underwent tracheoplasty.

The patient was a 2522 g, one-day-old trisomy-21 boy scheduled for colostomy for imperforate anus and was found to have a stenotic trachea at induction of anaesthesia. Tracheobronchogram revealed a long-segment tracheal stenosis starting just below the vocal cords to $1 \mathrm{~cm}$ above the carina, with the narrowest lumen of $1.5 \mathrm{~mm}$. Three sessions of balloon tracheal dilatation were performed to pass an endotracheal tube of $3.0 \mathrm{~mm}$ i.d. within a month. Three more sessions were required later because of the renarrowing by the granulation tissue.

Dilatation of the trachea was performed using a $4 \mathrm{Fr}$ angio-plasty balloon catheter introduced through the endotracheal tube during general anaesthesia. Pulse oximetry, capnography, electrocardiogram, invasive arterial pressure and temperature were monitored. The balloon was inflated with contrast medium at $8 \mathrm{~atm}$ for $30 \mathrm{sec}$, which was repeated three times with an interval to regain the haemodynamic stability.

In the anaesthetic management of patients undergoing balloon dilatation of the trachea or bronchus, the major concern is the coincidence of operative site and airway. Anaesthetic considerations include; (1) a possible loss of airway patency caused by surgical manipulation, accidental extubation, bleeding or trauma, (2) inability of lung ventilation during balloon inflation, (3) complications due to the use of contrast medium, including aspiration and bronchospasm ${ }^{1,2}$ and (4) possible pneumothorax, pneumomediastinum or pneumoperitoneum due to tracheal wall splitting. ${ }^{3}$

In the perioperative management, maintenance of airway patency is difficult even if the trachea is intubated. The placement of the tracheal tube itself and the suction manoeuvres entail the granulation formation, leading to the recurrent stenosis, which makes the management more difficult.

Keiko Kinouchi MD

Kazuo Fukumitsu MD

Muneyuki Takeuchi MD

Masami Matsuyama MD

Seiji Kitamura MD

Department of Anaesthesiology,

Osaka Medical Center and Research Institute for Maternal and Child Health

40 Murodo-cho

Izumi, 590-02 Osaka, Japan

\section{REFERENCES}

1 Cohen MD, Weber TR, Rao CC. Balloon dilatation of tracheal and bronchial stenosis. Am J Roentgenol 1984; 142: 477-8.

2 Brown SB, Hedlund GL, Glasier CM, Williams KD, Greenwood LH, Gilliland JD. Tracheobronchial stenosis in infants: successful balloon dilation therapy. Radiology 1987 ; $164:$ 475-8.
3 Bagwell CE, Talbert JL, Tepas JJ III. Balloon dilatation of long-segment tracheal stenoses. J Pediatr Surg 1991; 26: 153-9.

\section{No lipid droplets in blood during propofol anaesthesia}

To the Editor:

Propofol is a fatty emulsion which may induce lipid droplets in the blood and result in fat embolism or pulmonary oedema. The present study was designed to find out whether administration of propofol brings into existence of lipid droplets in the blood.

Ten adult patients (ASA physical status 1-2) undergoing elective surgery were studied. All had an internal jugular or subclavian venous catheter with the tip in the right atrium. Before general anaesthesia, $10 \mathrm{ml}$ blood was collected through the central venous catheter and plasma was separated. Subsequently, $2 \mathrm{mg} \cdot \mathrm{kg}^{-1}$ propofol were administered through a peripheral vein of the upper extremity and tracheal intubation was facilitated with $0.1 \mathrm{mg} \cdot \mathrm{kg}^{-1}$ vecuronium. General anaesthesia was maintained with $33 \% \mathrm{O}_{2} /$ air, fentanyl and continuous propofol infusion $\left(6-10 \mathrm{mg} \cdot \mathrm{kg}^{-1} \cdot \mathrm{hr}^{-1}\right)$. Fifteen minutes later, $10 \mathrm{ml}$ blood were collected from the right atrium and separated into plasma. Plasma was stirred with SudanIII dyes (plasma:SudanIII ratio 1:5) and examined microscopically $30 \mathrm{~min}$ later at a $\times 400$. There were no lipid droplets in any samples.

Some current reports describe pulmonary oedema appearing during propofol anaesthesia., ${ }^{1,2}$ However, other suggest that propofol does not aggravate pulmonary edema ${ }^{3-5}$ We considered that if propofol induced lipid droplets in the blood, pulmonary oedema may be attributed to embolism of lipid droplets in the peripheral lung vessels. The present results, however, deny our speculation. We conclude that propofol does not induce lipid droplets in the blood.

Hiroshi Iwama MD

Kazuhiro Watanabe MD

Toshikazu Kaneko MD

Takami Komatsu MD

Department of Anesthesiology

Central Aizu General Hospital

Aizuwakamatsu, Fukushima, Japan

REFERENCES

1 Borgeat A, Popovic V, Nicole A, Schwander D. Acute pulmonary oedema following administration of ornithine-8vasopressin. Br J Anaesth 1990; 65: 548-51.

2 Soto J, Sacristan JA, Alsar MJ. Pulmonary oedema due to fentanyl? (Letter) Anaesthesia 1992; 47: 913-4.

3 Kitson GE, Wauchob TD. Pulmonary oedema following carbamazepine overdose. Anaesthesia 1988; 43: 967-9.

4 Calder I, Ordman AJ, Jackowski S, Crockard HA. The Brain laryngeal mask airway. An alternative to emergency tracheal intubation. Anaesthesia 1990; 45: 137-9.

5 Donnelly JA, Webster RE. Computer-controlled anaesthesia in the management of bronchopleural fistula. Anaesthesia 1991; 46: 383-4. 